1 Universidade Federal do Espírito Santo (Ufes) - Vitória (ES), Brasil. Secretaria Estadual de Saúde do Estado do Espírito Santo - Vitória (ES), Brasil.

belasilva@saude.es.gov.br

2 Universidade Federal do Espírito Santo (Ufes), Departamento de Ciências da Saúde - Vitória (ES),

Brasil.

kallendw@gmail.com

3 Universidade Federal do Espírito Santo (Ufes), Departamento de Ciências da Saúde - Vitória (ES), Brasil.

dalbello.araujo@gmail.com

4 Universidade

Federal da Integração

Latinoamericana (Unila) -

Foz do Iguaçu (PR), Brasil.

gladysv@terra.com.br

\section{A importância do planejamento como prática de gestão na microrregião de saúde de São Mateus (ES)}

\author{
The relevance of planning as management practice in health micro \\ region of São Mateus (ES)
}

Bela Feiman Sapiertein Silva', Kallen Dettmann Wandekoken², Maristela Dalbello-Araujo ${ }^{\mathbf{3}}$, Gladys Amelia Vélez Benito 4

RESUMO Objetiva-se conhecer as representações sociais presentes nas narrativas das práticas dos gestores que atuam em São Mateus (ES), a respeito de como realizam o planejamento das ações e sobre a participação (ou não) dos trabalhadores e da população. A coleta indica duas ideias centrais: (1) planejamento - que é subdividida em: planejamento compartilhado; planejamento centralizado; e dificuldade de planejamento e (2) promover a participação popular. Conclui-se que os gestores, apesar de reconhecerem o valor de planejar as ações, praticam ações muito mais voltadas para a manutenção do sistema vigente do que para gerar mudanças com vistas à consolidação do SUS.

PALAVRAS-CHAVE Gestor de saúde; Planejamento em saúde; Sistema Único de Saúde.

ABSTRACT It aims to know the social representations present in the narrative of the practices of managers who work in São Mateus (ES), Brazil, into how they perform the planning of actions and about the participation (or not) of workers and population. The collection indicates two central ideas: (1) planning, which is subdivided into: common planning, centralized planning, difficulty of planning, and (2) fostering popular participation. It is concluded that managers, although they recognize the value of planning actions, they practice actions much more focused on the maintenance of the current system than for to generate changes in order to the consolidation of the Unified Health System (SUS).

KEYWORDS Health manager; Health planning; Unified Health System. 


\section{Introdução}

Ao considerar o planejamento um instrumento de gestão, apesar dos avanços alcançados, constata-se que a consolidação de uma cultura de uso do planejamento ainda é um grande desafio (BRASIL, 2009A). Para Noronha, Lima e Machado (2004, P. 65), há quatro grandes macrofunções gestoras:

(1) formulação de políticas e planejamento; (2) financiamento; (3) coordenação, regulação, controle e avaliação de ações, bens e serviços e dos sistemas de saúde; e (4) prestação direta de ações e serviços de saúde.

Mattos (2010), embasado na Teoria da Estruturação, afirma não ser tão fácil garantir se houve ou não planejamento para o desenvolvimento de uma dada ação, visto que o planejamento pode ser apenas uma forma conveniente de apresentação da referida ação (racionalização da ação). O planejamento registrado não necessariamente encaminhará a ação, uma vez que pode se limitar a uma exigência formal, mas não representar exatamente a intencionalidade do agente.

Nesse contexto, o autor apresenta uma crítica ao planejamento considerado normativo, proveniente de uma atividade técnica que não leva em consideração os fatores que explicam e determinam a realidade nem os coletivos envolvidos. Afirma que são estes, a partir de sua própria interpretação da realidade, que podem e devem direcionar um planejamento e sua operacionalização, de forma a atender às suas necessidades (MATTOS, 2010).

É nesse sentido que entendemos que a participação efetiva da sociedade na produção de saúde extrapola o arcabouço normativo e contribui para o exercício da cidadania, na medida em que o cidadão se posiciona não apenas como um receptor de serviços de saúde, mas como cocondutor do processo de planejamento e das políticas de saúde. Dessa forma, a participação social deixa de ser apenas "uma extensão burocrática e executiva, e passa a ser [...] um processo contínuo de democratização e de produção de sujeitos com maior autonomia" (ASSIS, 2003, P. 332). Garantir maior autonomia implica ampliar a capacidade reflexiva sobre si mesmo e sobre o contexto (CAMPOS, 1997). No entanto, essa proposta apresenta-se contrária aos interesses da sociedade contemporânea, que tem provocado o desestímulo à reflexão.

Para Bauman (2008), a manutenção da sociedade contemporânea está atrelada à irracionalidade dos consumidores e a uma economia do engano. Neste sentido, entende-se que se, por um lado, os avanços tecnológicos favorecem o acesso à informação de forma contínua e instantânea, por outro, há um desestímulo ao processo reflexivo e crítico da realidade. Se, por um lado, defende-se o uso da razão para a tomada de decisão, por outro, estimulam-se as atitudes imediatistas, levadas pela emoção do desejo, e as promessas de felicidade embutidas nas mercadorias disponíveis.

A participação dos trabalhadores da saúde na gestão dos serviços é garantida na Lei . $^{\circ}$ $8.142 / 90$, porém, na prática, apresenta-se incipiente, uma vez que o trabalhador se sente sobrecarregado no trabalho por considerar sua atuação complexa e, ainda, por estar submetido a uma gestão centralizadora e pouco participativa (BRASIL, 2009B). Entende-se que, para compreender a pouca participação dos trabalhadores, é importante uma reflexão da realidade apresentada no âmbito político, a partir da Reforma do Aparelho do Estado, em 1997, e das características da sociedade contemporânea.

Esse contexto traz em seu bojo uma tendência de transformar as pessoas em produtos que se apresentam à disposição no mercado. Campos (2007) afirma que há um esforço sistemático da política, do mercado, da gestão e de muitas instituições para 'coisificar' as pessoas e reduzi-las a objetos de pouca importância, em um processo de desumanização da vida social. Um dos componentes da globalização desumanizada é o desrespeito ao trabalho e ao trabalhador. 
O trabalhador passa a ser tratado como algo descartável (ROLLO, 2007).

Os vínculos humanos e as articulações coletivas são desvalorizados e enfraquecidos, valorizando-se a 'individualização' (BAUMAN, 2008). O imediatismo se sobrepõe aos pensamentos reflexivos e questionadores, e os interesses individuais superam os interesses coletivos.

Outro fator que contribui para essa desvalorização do trabalhador refere-se à Reforma Administrativa do Estado, que, sob o pretexto de alcançar seu objetivo de "permitir que a administração pública se torne mais eficiente e ofereça ao cidadão mais serviços, com maior qualidade" (BRASIL, 1997), direciona suas ações para os interesses privados. Em consequência, no final da década de 1990, o Sistema Único de Saúde (SUS) passa a adotar uma política de flexibilização, a qual acarretou a efetiva precarização das relações de trabalho nos âmbitos federal, estadual e municipal (BRASIL, 2009C). Simpatizantes da referida política apontam para o funcionalismo público "como os principais culpados pela ineficácia dos serviços públicos, o 'bode expiatório', e como tal não devem e não podem ser valorizados e bem cuidados" (ROLLO, 2007, P. 20).

Por outro lado, o processo de municipalização, que transfere a responsabilidade da contratação de pessoal para os municípios, tem limites inerentes à Lei de Responsabilidade Fiscal e à instabilidade administrativa e orçamentária. Além disso, tem poucas orientações sobre os procedimentos possíveis para atender concomitantemente às normativas legais e às especificidades exigidas pelos programas de saúde propostos pelo âmbito federal. Diante desse impasse, os municípios

tornaram-se os principais responsáveis pela contratação de trabalhadores e pelo gerenciamento dos serviços, utilizando, inclusive, parcerias com Organizações Não Governamentais (ONGs), Organizações da Sociedade Civil de Interesse Público (Oscips) ou contratos com cooperativas. (BRASIL, 2006, P. 12).
Estudos realizados pelo Ministério da Saúde (MS), em 2001/2002, apontam que cerca de 20 a $30 \%$ de todos os trabalhadores inseridos na Estratégia Saúde da Família apresentavam vínculos precários de trabalho (BRASIL, 2006). O trabalho precário envolve uma série de situações decorrentes da fragilidade dos vínculos de trabalho e acarreta

um alto grau de desmotivação dos profissionais e consequentemente grande rotatividade desses trabalhadores nos serviços, prejudicando a continuidade das políticas e programas de atenção à saúde da população. (BRASIL, 2006).

A precarização do trabalho está relacionada com o não cumprimento das normas administrativas e dos direitos trabalhistas. Assim, as relações de trabalho se dão sem os direitos e benefícios constitucionais assegurados, isto é, sem a efetiva proteção social ao trabalhador. As normativas legais apresentam brechas que possibilitam distintas formas de contratação, $o$ que dificulta a efetiva garantia de uma proteção social. O MS reconhece que a precarização do trabalho é um problema que afeta a consolidação do SUS e sinaliza como prioridade a formulação de políticas que contribuam para solucionar essa questão (BRASIL, 2009C).

Para tanto, o MS, por meio do Departamento de Gestão e da Regulação do Trabalho em Saúde, criou o Programa Nacional de Desprecarização do Trabalho no SUS - DesprecarizaSUS (BRASIL, 2006), com o objetivo de implantar uma política de valorização do trabalhador. Diante de uma proposta de mudança, para alcançar os objetivos do SUS, o MS ressalta a Política Nacional de Humanização $(\mathrm{PNH})$, visando à valorizar e garantir a participação de todos os sujeitos envolvidos na produção de saúde no processo de gestão, à ampliação da autonomia, ao protagonismo, à corresponsabilidade e ao estabelecimento de vínculos solidários (BRASIL, 2009B).

A PNH apresenta a gestão participativa como uma ferramenta de importância para a construção de mudanças nos modos de gerir 
e nas práticas de saúde, de forma a contribuir para que o atendimento seja mais eficaz/ efetivo e motivador para o trabalhador. "A cogestão é um modo de administrar que inclui o pensar e o fazer coletivo, sendo, portanto, uma diretriz ético-política que visa democratizar as relações no campo da saúde" (BRASIL, 2009B, P. 10).

Assim, a cogestão implica a inclusão de vários sujeitos nos processos de gestão, que

seria exercida [...] por um conjunto mais ampliado de sujeitos que compõem a organização, assumindo-se o predicado de que 'todos são gestores de seus processos de trabalho. (BRASIL, 2009B, P. 24).

Logo, diante dessas considerações, neste artigo, propusemo-nos a conhecer as representações sociais presentes nas narrativas das práticas dos gestores municipais de saúde, que atuam em alguns municípios da região Norte do estado do Espírito Santo, a respeito de como realizam o planejamento das ações, inquirindo, também, se há participação dos trabalhadores e da população nesse processo.

\section{Método}

Realizou-se um estudo exploratório, pautado em uma abordagem qualitativa, no qual foram entrevistados 16 secretários de saúde que atuam ou atuaram em nove municípios que compõem a microrregião São Mateus (ES).

A coleta de dados, realizada nos meses de outubro a dezembro de 2011, deu-se a partir de um roteiro semiestruturado, focado em uma questão principal: relate sobre sua rotina e as ações que desenvolve em seu dia a dia como secretário da saúde.

Diante dos objetivos propostos, este estudo se baseou na Teoria das Representações Sociais, a qual se refere a um conjunto de opiniões, crenças, valores, atitudes, imagens e normas partilhadas por um grupo de indivíduos num determinado momento histórico, sobre um determinado fenômeno, produzidas a partir do seu cotidiano e que direcionam as suas formas de pensar e agir (SANTIAGO, 2010). Para análise do material, nessa perspectiva, utilizou-se a técnica do Discurso do Sujeito Coletivo (DSC), criado por Lefèvre e Lefèvre (2004), que propõe a construção de discursos-síntese, redigidos na primeira pessoa do singular, compostos por Expressões-Chave (ECH), encontrados nos depoimentos e organizados por Ideias Centrais (IC) e/ou ancoragens. Assim, o DSC busca a reconstituição discursiva de parte da(s) representação(ções) social(is) de uma coletividade, como se esta fosse a emissora de um discurso.

Para auxiliar no processamento dos depoimentos e na construção dos DSCs, foi utilizado o programa Qualiquantisoft, versão $1.3 \mathrm{c}$, desenvolvido na Faculdade de Saúde Pública da Universidade de São Paulo (USP) por Lefèvre e Lefèvre, em parceria com Sales \& Paschoal Informática (QUalIQUANTISOFT, 2010). O software citado foi utilizado para dar suporte ao método em uso, a partir da licença de uso acadêmico, e contribuiu para a organização e compilação dos dados, bem como para o cálculo quantitativo dos resultados.

Foram atendidas as prerrogativas da Resolução n. ${ }^{\circ}$ 196/96, do Conselho Nacional de Saúde para Pesquisa Científica em Seres Humanos (BRASIL, 1996), sendo aprovado, sob o número de registro 233/10, pelo Comitê de Ética em Pesquisa (CEP) da Universidade Federal do Espírito Santo.

\section{Resultados}

Os resultados quantitativos sobre a percepção dos gestores com relação às ações que desenvolvem apontaram 11 ideias centrais, de forma que, para algumas, foi construído mais de um discurso, por entender que apresentavam representações distintas. Assim, foram consideradas: a ideia central 'planejamento' - que se subdivide em 1.1 planejamento compartilhado; 1.2 planejamento centralizado; e 
1.3 dificuldade de planejar - e a ideia central 'fomento da participação popular'. Seguem abaixo os discursos:

\section{Planejamento}

\subsection{PLANEJAMENTO COMPARTILHADO}

Como gestor, você tem que planejar, então, pra mim, o planejamento é o carro-chefe, é o mestre, é o objeto. Eu tenho que planejar pra executar. A gente faz o planejamento todo ano, convoca, praticamente fecha a secretaria, tirando os serviços essenciais, faz uma reunião bem sortida de profissionais pra gente ser o mais próximo da realidade das regiões. Essa é a forma da gente fazer esse planejamento. Tira, em média, 1 dia pra fazer esse planejamento, onde que fica definida a ação, a equipe responsável, com nome, CPF, com prazo de execução e o produto esperado. Então, faz aquele plano de ação de tudo, bem complexo. Os dois planos: é o de um ano e o de 3, 4 anos. Então, fazer isso daí, faz no início, até uma dedicação a mais. É feito por mim, pela coordenação do PSF e os enfermeiros da ESF. Então, na verdade, nós temos um projeto que foi montado junto com a equipe no início do mandato. Eu sentei com os gerentes, depois nós traçamos o projeto. Também temos durante a semana reunião com todos os coordenadores, onde se avaliam as metas da semana anterior que foram cumpridas e definem-se as metas que eles vão trabalhar, que nós vamos trabalhar nessa semana. Também, a gente pensa muito no planejamento, quando nós temos que ir pra $\mathrm{CIB}^{1}$ pactuar, aí nós precisamos pensar com quem nós vamos pactuar o serviço que nós não estamos conseguindo atender. E tem outra situação que eu falava assim: - olha, tem um projeto. Vai sair vinte mil para alguma coisa, então escreve.

\subsection{PLANEJAMENTO CENTRALIZADO}

Eu tenho que, como secretário, não só gerenciar, mas essa parte de planejamento, de captação de recurso, de fazer plano de trabalho de convênio. Eu que acabo tendo que fazer, junto com um coordenador que fica na parte de administração de saúde. Então, eu consegui colocar uma pessoa que fica responsável pra elaborar plano de gestão, está elaborando as audiências junto com essas informações que as outras vigilâncias passam. Vigilância, agendamento, aí passa as informações pra ela, ela senta, elabora, depois a gente pega e vê se está de acordo. Pra fazer o projeto da secretaria, eu, pessoalmente, fiz um diagnóstico do município. Também, eu precisava ir pros assentamentos - não tem como você fazer propostas de intervenção dentro de um município se você não tem diagnóstico de área definido, então, você precisa conhecer, e o que os olhos veem, não tem jeito. Por mais que as pessoas queiram construir isso pra você, sem você visualizar, sem você ter o contato com o povo, não tem como você realmente construir uma proposta de intervenção. Também acho importante você pegar e ir nas unidades e presenciar o que, frente a frente, aquela unidade está necessitando. Outro é o hospital, a AMA ${ }^{2}$, o centro médico, já vejo como está, vejo a demanda que tem.

\subsection{DIFICULDADE DE PLANEJAR}

A minha atividade mais importante é justamente planejar, e eu tento dar essa prioridade pro meu trabalho, só que eu não consigo. É aquela história, a gente acaba tendo que apagar muito incêndio. Muitas vezes a gente planeja as coisas e não consegue executar, por causa da correria. Eu acho que o que o secretário de saúde tem que fazer é planejar a promoção e a prevenção, isso é o mais importante, mas a gente acaba lidando muito com a doença, a gente acaba dando prioridade pra assistência, e eu não acho que essa deveria ser minha prioridade. A verdade é essa: por mais que a gente queira e tente trabalhar com planejamento, tem muita coisa do dia a dia que não está devidamente organizado e que acaba trazendo transtorno de tirar gente
1 Comissão Intergestores Bipartite

2 Assistência Médica Ambulatorial 
da agenda. Então, assim, um ponto falho meu é esse, de me empenhar muito realmente nos resultados da execução e não pensar tanto no planejamento. Porque você trabalha muito como bombeiro, né? Você apaga muito incêndio, então, assim, as demandas vão surgindo e você vai se envolvendo nelas, e, no momento de planejar, de acompanhar, de estar monitorando as ações como um todo do município, isso daífica, talvez, até meio deficiente, por essa falta mesmo de tempo, então, a gente acaba fazendo um pouco de cada coisa, e pra chegar no final do ano e estar lá com as nossas metas alcançadas. Sabe, eu acho que fazer o planejamento, talvez, não é tão difícil. O mais difícil da gente é acompanhar.

\section{Fomento da participação popular}

A gente faz as audiências públicas itinerantes rigorosamente, criteriosamente. Nós convidávamos as escolas, convidamos as lideranças, a população, pra elas irem debater e estarem participando e saber onde estão sendo investidos os recursos da saúde. A gente faz as reuniões com todas as comunidades pra saber o que eles pensam sobre a saúde, de prestar contas, de tentar fazer com que eles, até através de caixinha de sugestões em todas as unidades, em todos os setores, pra que as pessoas possam opinar, e nós abrimos todo final de mês para ver o que as pessoas estão dizendo do nosso serviço, ou de alguns setores. E, nas reuniões, eu levo o que foi dito daquela comunidade, daquela unidade. Olha, foi dito isso e isso, nós vamos poder, em cima disto, melhorar isso, ou isso não vai ser possível fazer. Sabe, pra mim, levar ao cidadão nas reuniões que a gente faz nas comunidades e de que eles têm mais direito que podiam imaginar, mas também tem um compromisso muito maior com a qualidade de vida deles do que eles estão exercendo. Isso aí também é fundamental. Bom, pra mim não existe o secretário sem o Conselho. Tem que ter o Conselho de Saúde parceiro e também para nortear, pra regular de alguma forma, e até a participação popular mesmo. Então, nós conseguimos fazer esse espaço pro Conselho, então a gente sempre deixa as informações da saúde nesse lugar, nesse espaço, com essa porta de acesso, tanto pros conselheiros, mas também pros usuários que fazem parte, que as pessoas podem chegar lá e ter acesso às nossas contas, ter acesso às nossas ações, aos programas desenvolvidos. Nós começamos a fazer reuniões do Conselho itinerante, e tudo que nós levantamos como demanda que a população coloca, nós procuramos atender. Então, hoje, se a gente fizer uma avaliação, uma pesquisa, acredito que a gente tem uma avaliação melhor. Por outro lado, eu acho que o Conselho de Saúde tem um poder muito grande, mas eu não sei se por medo, por amizade, por falta de conhecimento ou por falta de capacitação dos conselheiros, mas, na realidade, eles não têm conhecimento do seu papel. Não funciona. As contas são aprovadas sem procurar saber; os projetos, às vezes, são aprovados e não há um questionamento. Na prática, eu vou te explicar o que é um Conselho de Saúde numa cidade do interior, porque não é só aqui que é assim: são pessoas, geralmente, sem muita instrução, que não têm muito conhecimento. Quando a gente vai ter eleição pro Conselho de Saúde, escolha dos conselheiros, a gente manda a cartinha solicitando os representantes pra várias instituições. Ninguém quer participar. Então, a gente conversa muito com essas pessoas, mas muita coisa não está ao alcance delas, por exemplo, um relatório de gestão. Eu fico com dó de apresentar o relatório de gestão pra eles, porque a gente tem que esmiuçar. Dá um trabaIho tão grande! E eu sei que, no fundo, no fundo, muita coisa eles não entendem porque eles não têm preparação pra isso. Precisa capacitação constante de Conselho. Só que, quando a gente consegue que o Conselho esteja mais ou menos capacitado, já está na hora de mudar, aí já vêm outros membros, entendeu? Conselho no Brasil, sinceramente, é só pra ter nome. Eu vejo assim. Os grandes Conselhos, Conselhos Estaduais, o Conselho Nacional, eles sim têm cabeças pensantes, que vão fazer a diferença. Pelo menos, é o que a gente espera. 


\section{Discussão}

O discurso sobre o planejamento, como uma das ações realizadas pelos secretários municipais de saúde, representou 8,93\% das 112 respostas. Porém, chama a atenção o fato de que $70 \%$ dos gestores que expressaram essa ideia central pertencem ao grupo dos gestores atuais. Ainda, vale ressaltar que os dois únicos gestores atuais que não participaram da construção desse discurso são gestores que estão no cargo há menos de um ano. A associação desses dois dados quantitativos nos leva a pensar que os gestores têm percebido, gradativamente, a complexidade da gestão da saúde e a necessidade de uma atuação técnica, principalmente a partir da transferência de responsabilidade cada vez maior para a gestão no âmbito municipal.

Conforme explicitado anteriormente, foram elaborados três DSCs para a IC. O $1^{\circ}$ aponta para uma prática de planejar compartilhada; o $2^{\circ}$ expressa um planejamento mais centralizado; e o $3^{\circ}$, e mais expressivo, aponta a dificuldade encontrada pelo gestor para planejar.

Do item 1.1, em 'planejamento compartilhado', destaca-se o seguinte trecho: "Como gestor, você tem que planejar, então, pra mim, o planejamento é o carro-chefe, é o mestre, é o objeto. Eu tenho que planejar pra executar [...]".

O discurso identifica o planejamento como uma das ações mais importantes da gestão. Concomitantemente, no entendimento do gestor, essa ação não é garantida devido a diversos fatores, entre eles, a correria do cotidiano; a falta de organização e o excesso de empenho nos resultados da execução e nas demandas que surgem, definidas no discurso como 'incêndios', como podemos observar no trecho do item 1.3:

É aquela história, a gente acaba tendo que apagar muito incêndio. Muitas vezes, a gente planeja as coisas e não consegue executar, por causa da correria [...] Porque você trabalha muito como bombeiro, né? Você apaga muito incêndio, então, assim, as demandas vão surgindo e você vai se envolvendo nelas, e, no momento de planejar, de acompanhar, de estar monitorando as ações como um todo do município, isso daí fica, talvez, até meio deficiente, por essa falta mesmo de tempo.

Assim, a postura de 'bombeiros' é enfatizada frente às demandas que emergem e tornam o cotidiano dinâmico, requerendo do gestor agilidade nas respostas e condutas. Nesse contexto, entende-se que essa posição está relacionada às exigências da sociedade contemporânea, uma vez que são valorizadas respostas rápidas em detrimento daquelas que demandam tempo, como é o caso do planejamento.

Além disso, outra questão levantada é que as ações planejadas nem sempre são concretizadas, como pode-se ver no trecho do item 1.3: "Sabe, eu acho que fazer o planejamento, talvez, não é tão difícil. O mais difícil da gente é acompanhar".

Entende-se que essa realidade, além de estar associada aos fatores conjunturais acima descritos, está relacionada com a forma com que os gestores compreendem o processo de planejamento. Observa-se que a representação do planejamento está fortemente atrelada a exigências do âmbito federal, no que se refere à elaboração e ao preenchimento de planos e planilhas.

Atualmente, o desempenho da função do gestor exige o desenvolvimento de um leque de atividades, entre elas, a elaboração e a apresentação de instrumentos de planejamento às demais instâncias governamentais. Neste sentido, os gestores fazem referência, mesmo sem especificação nominal, ao Plano Plurianual (PPA), Plano Anual de Saúde (PAS) e Programação Pactuada e Integrada da Assistência (PPI), como observa-se nos trechos dos itens 1.1:

A gente faz o planejamento todo ano, convoca, praticamente fecha a secretaria, tirando os serviços essenciais, faz uma reunião bem sortida 
de profissionais pra gente ser o mais próximo da realidade das regiões [...] Então, faz aquele plano de ação de tudo, bem complexo. Os dois planos: é o de um ano e o de 3, 4 anos. Então, fazer isso daí, faz no início, até uma dedicação a mais. É feito por mim, pela coordenação do PSF e os enfermeiros da ESF [...] Também, a gente pensa muito no planejamento, quando nós temos que ir pra CIB pactuar, aí nós precisamos pensar com quem nós vamos pactuar o serviço que nós não estamos conseguindo atender.

No discurso, não expressam a 'utilização viva' dos referidos instrumentos de gestão, isto é, fazem referência sobre a sua elaboração, porém, não os apresentam como instrumentos norteadores da ação. A PPI é apresentada como uma oportunidade de se falar sobre planejamento em espaços de negociação microrregionais, porém, percebe-se que os três instrumentos são tidos como uma obrigatoriedade a ser cumprida, e não como um instrumento de apoio à gestão, fato que pode estar atrelado à dificuldade dos mesmos em identificá-los pelos nomes.

Os discursos apresentam a realização de projetos específicos, objetivando a obtenção de recursos federais. Essa iniciativa reflete a representação do gestor com relação à elaboração de projetos como oportunidades para obtenção de recursos, e não, necessariamente, enquanto oportunidade de direcionar projetos para atender às necessidades locais, como destacado do item 1.1: "E tem outra situação que eu falava assim: - olha, tem um projeto! Vai sair vinte mil para alguma coisa, então escreve".

Essa prática pode possibilitar a oferta de novos serviços aos usuários, vindo ao encontro de algum desejo ainda não atendido ou para estimular novos desejos, ou pode se tornar apenas mais um projeto sem utilização prática.

Outro aspecto apresentado refere-se à estratégia utilizada pelos gestores para a elaboração do planejamento. Verifica-se que grande parte dos sujeitos que compuseram o discurso sobre planejamento expressou a participação da equipe na elaboração do planejamento, construindo, assim, o DSC 'planejamento compartilhado', e, ainda, que a maioria deles também compôs o DSC 'planejamento centralizado', no qual identifica-se que o gestor assume para si a responsabilidade de realizar o planejamento, mesmo que, em alguns casos, haja o envolvimento de um colaborador, como se observa nos trechos dos itens 1.1 e 1.2, respectivamente: "Então, na verdade, nós temos um projeto que foi montado junto com a equipe no início do mandato. Eu sentei com os gerentes, depois nós traçamos o projeto”.

Eu tenho que, como secretário, não só gerenciar, mas essa parte de planejamento, de captação de recurso, de fazer plano de trabalho de convênio. Eu que acabo tendo que fazer junto com um coordenador, que fica na parte de administração de saúde.

Como pode-se observar, parte dos entrevistados participa de ambos os discursos, não deixando clara a percepção dos mesmos com relação à forma de encaminhar o planejamento ou evidenciando que não possuem um único entendimento. $\mathrm{Ou}$, ainda, que expressam um compartilhamento dessa ação, porém, na prática, acabam por assumir individualmente.

Observa-se que o discurso sobre 'planejamento compartilhado' expressa a participação da equipe em momentos pontuais de construção dos planos; a tentativa, ainda que incipiente, de monitoramento; discreta referência à troca de saberes entre os profissionais e ausência de participação social no processo. Já o discurso sobre 'planejamento centralizado' busca romper com a perspectiva centralizada ao apresentar a participação de um colaborador para elaborar o planejamento.

Outro ponto que chama a atenção refere-se ao destaque dado à elaboração de um diagnóstico da situação, que é fortemente valorizado 
como uma ação que deve ser realizada in loco e pessoalmente pelo gestor, a fim de garantir efetividade da gestão, porém, é pouco expressa a associação desse diagnóstico com as ações planejadas ou realizadas, como observa-se no trecho extraído do item 1.2 :

Pra fazer o projeto da secretaria, eu, pessoalmente, fiz um diagnóstico do município. Também, eu precisava ir pros assentamentos. - não tem como você fazer propostas de intervenção dentro de um município se você não tem diagnóstico de área definido, então você precisa conhecer, e o que os olhos veem, não tem jeito. Por mais que as pessoas queiram construir isso pra você, sem você visualizar, sem você ter o contato com o povo, não tem como você realmente construir uma proposta de intervenção. Também acho importante você pegar e ir nas unidades e presenciar o que, frente a frente, aquela unidade está necessitando.

Essa prática exala uma representação de que o olhar do responsável é a garantia do bom funcionamento do serviço. Assim, valoriza-se o papel do gestor e reafirma-se a superioridade técnica do mesmo em relação aos outros profissionais. O discurso ainda expressa a representação de que as visitas às diversas unidades e o contato com os profissionais e usuários são práticas de uma gestão comprometida e presente.

Além disso, o discurso sugere o entendimento de que o planejamento de ações de prevenção e promoção da saúde deveria ser priorizado, como destacado no trecho do item 1.3:

Eu acho que o que o secretário de saúde tem que fazer é planejar a promoção e a prevenção, isso é o mais importante, mas a gente acaba lidando muito com a doença, a gente acaba dando prioridade pra assistência, e eu não acho que essa deveria ser minha prioridade.

Mais uma vez, o discurso aponta, assim como outros DSCs já apresentados, para a representação do gestor de uma dicotomia entre as ações de prevenção de doenças e promoção da saúde e as ações de assistência. Nesse sentido, parece que os 'incêndios' que surgem (e inviabilizam o planejamento de ações de prevenção e promoção) referem-se às ações assistenciais, o que reforça a hegemonia, na prática, do modelo médico assistencial.

Já a IC 'fomento da participação popular' representa 5,36\% do total de 112 respostas encontradas na pesquisa, e ocupa o último lugar entre as representações sinalizadas pelos gestores.

O discurso aponta para a participação da população em dois espaços diferentes de produção da saúde:

A gente faz as reuniões com todas as comunidades pra saber o que eles pensam sobre a saúde, de prestar contas, de tentar fazer com que eles, até através de caixinha de sugestões em todas as unidades, em todos os setores, pra que as pessoas possam opinar, e nós abrimos todo final de mês para ver o que as pessoas estão dizendo do nosso serviço, ou de alguns setores. $E$, nas reuniões, eu levo o que foi dito daquela comunidade, daquela unidade [...] Tem que ter - Conselho de Saúde parceiro e também para nortear, pra regular de alguma forma, e até a participação popular mesmo.

O primeiro refere-se aos espaços não formais, como, por exemplo, as próprias unidades de saúde, através da caixa de sugestões nas reuniões com comunidades. Já o segundo refere-se aos espaços formalmente constituídos, como os conselhos municipais de saúde.

Ambos os espaços são valorizados como possibilidades para aproximar a população do gestor, com o objetivo de prestar contas, conhecer a opinião da população acerca dos serviços e identificar suas expectativas com relação aos mesmos.

De forma geral, afirma que o gestor procura atender às necessidades apontadas ou, pelo menos, esclarecer sobre a 
impossibilidade de atender. A preocupação em dar respostas à população é assinalada no discurso a partir de dois entendimentos: o primeiro refere-se à importância atribuída à construção de uma relação horizontalizada envolvendo o usuário, o trabalhador e o gestor; e o segundo, uma estratégia de obter uma boa avaliação de desempenho.

A primeira resgata o propósito da participação social prevista no SUS, e a segunda aponta para fatores que extrapolam o sistema de saúde e podem estar relacionados com interesses políticos ou interesses de mercado. Outro ponto que o discurso levanta é a importância desses espaços para orientar os usuários sobre os seus direitos e deveres para a própria saúde. Emerge uma representação de que, apesar de a saúde ser um direito do cidadão e um dever do Estado, o cidadão deve assumir a própria saúde como um dever. Nesse sentido, este passa a ser responsabilizado tanto pelo seu adoecimento quanto pelo seu cuidado, reproduzindo o interesse do Estado de transferência de responsabilidade aos indivíduos.

No tocante ao Conselho Municipal de Saúde, espaço formal de participação social, garantido a partir da Lei n. ${ }^{\circ} 8.142 / 90$, ainda que afirmado no discurso como um espaço importante no encaminhamento dos serviços de saúde, é apresentado sob dois enfoques: por um lado, o discurso aponta para iniciativas do gestor de fortalecer esse espaço e fomentar a participação social. Por outro, o discurso apresenta uma descrença com relação a essa participação, como destacado nos trechos abaixo:

Então, nós conseguimos fazer esse espaço pro Conselho, então a gente sempre deixa as informações da saúde nesse lugar, nesse espaço, com essa porta de acesso, tanto pros conselheiros, mas também pros usuários que fazem parte, que as pessoas podem chegar lá e ter acesso às nossas contas, ter acesso às nossas ações, aos programas desenvolvidos [...] Por outro lado, eu acho que o Conselho de Saúde tem um poder muito grande, mas eu não sei se por medo, por amizade, por falta de conhecimento ou por falta de capacitação dos conselheiros, mas, na realidade, eles não têm conhecimento do seu papel. Não funciona. As contas são aprovadas sem procurar saber; os projetos, às vezes, são aprovados e não há um questionamento.

Esses dois pontos, ainda que pareçam contraditórios, são apresentados em um único discurso, pois os próprios gestores os apresentam conjuntamente. Entende-se que alguns fatores contribuem para isso: primeiramente, pelo fato de o discurso institucional do SUS apresentar a participação social com destaque, o que acaba repercutindo no próprio discurso do gestor. Em segundo lugar, o gestor, ainda que esteja descrente com relação ao papel do conselho, pode estar buscando estratégias para mudar esse quadro. A nosso ver, os dois pontos acima podem estar presentes conjuntamente.

Outro aspecto que consideramos importante refere-se aos propósitos atribuídos aos conselhos. Ainda que este seja apresentado como norteador e regulador do sistema, o que prevalece no discurso é uma perspectiva voltada para uma participação mais pontual, isto é, momentos específicos para que a população possa se aproximar do gestor e apresentar sua opinião e/ou suas expectativas:

Nós começamos a fazer reuniões do Conselho itinerante, e tudo que nós levantamos como demanda que a população coloca, nós procuramos atender. Então, hoje, se a gente fizer uma avaliação, uma pesquisa, acredito que a gente tem uma avaliação melhor.

A participação efetiva dos conselhos municipais no planejamento, no encaminhamento e no monitoramento das políticas públicas não é referida. O discurso afirma que, na percepção do gestor, os conselhos municipais não desempenham seu papel. Várias são as justificativas apontadas, e entre elas está o desinteresse da maioria da população: 
Quando a gente vai ter eleição pro Conselho de Saúde, escolha dos conselheiros, a gente manda a cartinha solicitando os representantes pra várias instituições. Ninguém quer participar.

Essa realidade reflete a própria história do País, caracterizada pelo regime de exceção. Esse traço sociopolítico é fortalecido pelos interesses da sociedade contemporânea, que não estimula os movimentos de organização social e incentiva as iniciativas individuais, com vistas a atender aos desejos pessoais, $o$ que reforça os 'silêncios populares' apontados no discurso.

Outra justificativa apontada refere-se à falta de conhecimento e de formação dos conselheiros:

[...] eu acho que o Conselho de Saúde tem um poder muito grande, mas eu não sei se por medo, por amizade, por falta de conhecimento ou por falta de capacitação dos conselheiros, mas, na realidade, eles não têm conhecimento do seu papel. Não funciona. As contas são aprovadas sem procurar saber; os projetos, às vezes, são aprovados e não há um questionamento [...] E eu sei que, no fundo, no fundo, muita coisa eles não entendem porque eles não têm preparação pra isso. Precisa capacitação constante de Conselho. Só que, quando a gente consegue que o Conselho esteja mais ou menos capacitado, já está na hora de mudar, aí já vêm outros membros, entendeu?

Esse ponto levanta duas questões que consideramos importantes: 1) Reflete a representação que o gestor tem do usuário do SUS, associando-o a uma população de pouca instrução, incapaz de compreender os problemas do setor. Dessa forma, fortalece-se a imagem de um sistema de saúde para pobres, distanciado de segmentos populacionais com melhores condições socioeconômicas. Além disso, aponta para um conselho de saúde frágil.

2) Sugere o entendimento do gestor sobre o conhecimento. Revela a representação de que o conhecimento está atrelado ao grau de instrução do indivíduo. Consequentemente, o senso comum não é reconhecido como uma das formas de conhecimento. Assim, uma pessoa que não detém o conhecimento técnico, não tem condições de contribuir para a construção e o encaminhamento das políticas públicas.

Para que os conselheiros possam adquirir os conhecimentos técnicos, o gestor sugere capacitações e encara essa ação como uma forma de transmissão de conhecimento, resgatando a concepção ‘bancária' da educação, apresentada por Freire (1983).

Os conselhos não são percebidos como potência para contribuir no planejamento das ações. Assim, entende-se que a forma com que o gestor percebe a participação social está distante da proposta de uma gestão compartilha, com vistas à consolidação da democracia.

O Ministério da Saúde afirma que os usuários têm pouca participação nesse processo, porém, aponta para uma ampliação gradativa dessa participação (BRASIL, 2009B). No entanto, pelo discurso apresentado, o gestor não percebe esse avanço com relação à atuação dos conselhos municipais e afirma que eles só existem formalmente, porém, não funcionam. Já, ao se referir aos conselhos estaduais e federal, afirma que esses têm maior representatividade.

O discurso sugere a representação de que os municípios, com ênfase nos municípios do interior, têm uma população menos instruída, incapaz de ter posicionamentos interessantes, como observa-se no trecho do item 2:

Na prática, eu vou te explicar o que é um Conselho de Saúde numa cidade do interior, porque não é só aqui que é assim: são pessoas, geralmente, sem muita instrução, que não têm muito conhecimento.

Esse entendimento levanta alguns questionamentos: se as pessoas do interior são menos qualificadas do que as pessoas das outras esferas federadas para dar 
contribuições e sugestões aos encaminhamentos das políticas de saúde, esse mesmo entendimento não estaria também presente com relação aos gestores municipais e aos de outra esfera? Como construir uma relação interfederativa mais horizontalizada se o próprio gestor, que é do interior, percebe o interior como um local dotado de menor capacidade?

Entende-se que, para investir esforços em uma ideia, deve-se acreditar nela. Assim, para investir nos conselhos, seria necessário acreditar que eles podem funcionar. Neste sentido, se, por um lado, a população ainda não assumiu o seu papel, conforme o discurso afirma, o gestor também não concretizou arranjos e dispositivos que possam contribuir para ampliar a capacidade reflexiva dos atores envolvidos na produção de saúde e, consequentemente, para a efetivação de uma gestão compartilhada, prevista na Política Nacional de Humanização.

A maneira com que a participação social é apresentada reforça os princípios da lógica do mercado, que não tem interesse em investir em ações que contribuam para práticas reflexivas que possam dificultar ou inviabilizar a sua manutenção. A partir dessa (ir)racionalidade, segundo Bauman (2008), a sociedade produz mecanismos para absorver discordâncias que ela mesma produz, e, assim, busca garantir a sua própria manutenção.

Entende-se que as estratégias utilizadas pelo gestor para fomentar a participação social tanto podem ser mecanismos para absorver discordâncias e garantir a sua manutenção quanto podem ser espaços singulares para fomentar o empoderamento da população e produzir mudanças sociais.

\section{Considerações finais}

Considerando a proposta de conhecer as representações sociais dos gestores a respeito de como realizam o planejamento, além de entender se há ou não participação dos trabalhadores e da população nesse processo, a partir da maioria dos discursos, constatou-se que, ainda que os gestores entendam a importância do planejamento enquanto ação prioritária para organizar os serviços, há inviabilidade dessa prática em decorrência de episódios tidos como 'incêndios', os quais demandam respostas ágeis, voltadas para a assistência, de forma que as práticas muitas vezes são encaminhadas pelos gestores sem uma reflexão sobre as mesmas. Contraditoriamente, outro discurso vislumbra o fato de que os gestores ocupam tempo considerável com atividades não prioritárias.

Além disso, constatou-se que as ações planejadas nem sempre são realizadas, o que, em muitos casos, relaciona-se com a forma como os gestores entendem o planejamento. Entre as estratégias utilizadas para sua elaboração, nota-se que, na maioria dos discursos, prevalecem ideias destoantes - como o 'planejamento compartilhado', em associação com o 'planejamento centralizado'. E, ainda, os gestores sugerem a priorização das ações de prevenção e de promoção de saúde.

Considera-se que um planejamento com vistas ao encaminhamento de ações pautadas no princípio da integralidade prevê as ações de prevenção, promoção, tratamento e reabilitação, de forma indissociável, além de garantir, efetivamente, a participação de todos os atores envolvidos. Ainda, entende-se que o planejamento deve ser um 'instrumento vivo' que realmente acompanhe o dia a dia da produção de saúde, a fim de que as exigências impostas pela sociedade contemporânea, identificadas no discurso como 'incêndios', não se sobreponham às ações e aos compromissos assumidos coletivamente.

Já no tocante ao 'fomento da participação popular', os discursos indicam a participação da população em espaços não formais e formais, como o conselho municipal. Com relação a este último, os discursos apontam ideias opostas, de forma que uma busca 
valorizar a participação social, e a outra desacredita nessa possibilidade.

Além disso, não se referem à participação do conselho em atividades como planejamento e monitoramento das políticas; e, ainda, acreditam que o conselho municipal não desempenha sua função, uma vez que há desinteresse de grande parte dos envolvidos ou há conhecimento e formação precários dos conselheiros para o desenvolvimento de tal atividade. Assim, para os gestores, os conselhos não possuem potência para colaborar no planejamento das ações, o que reforça a lógica do mercado.

Neste sentido, vislumbra-se uma possibilidade de empoderamento da população, como um conjunto de sujeitos ativos, com vistas a gerar mudanças no encaminhamento da saúde regional. Porém, as iniciativas apontadas, a nosso ver, apresentam-se muito mais voltadas para a manutenção do sistema vigente do que para gerar mudanças no processo de gestão com vistas à consolidação do SUS.

\section{Referências}

ASSIS, M. M. A. O processo de construção do controle social no Sistema Único de Saúde e a gestão nos espaços institucionais. Saúde em Debate, Rio de Janeiro, v. 27, n. 65, p. 324-335, set./dez. 2003.

BAUMAN, Z. Vida para o consumo: a transformação das pessoas em mercadorias. Tradução: Carlos Alberto Medeiros. Rio de Janeiro: Jorge Zahar Ed., 2008.

BRASIL. Ministério da Administração Federal e Reforma do Estado. A Reforma do aparelho do estado e as mudanças constitucionais: síntese e respostas a dúvidas mais comuns. Brasília, DF: MARE, 1997. 23 p.

Ministério da Saúde, Organização PanAmericana da Saúde. Sistema de Planejamento do SUS (PlanejaSUS): uma construção coletiva - trajetória e orientações de operacionalização. Brasília, DF, 2009a.

Ministério da Saúde. Conselho Nacional de Saúde. Resolução n. ${ }^{\circ}$ 196/1996. Dispõe sobre as diretrizes e normas regulamentadoras de pesquisa envolvendo seres humanos. Bioética. n. 4, supl. 2, p. 5-25, 1996.

Ministério da Saúde. Secretaria de Atenção à Saúde. Política Nacional de Humanização da Atenção e Gestão do SUS. Gestão participativa e cogestão. Brasília, DF, 2009b.
Ministério da Saúde. Secretaria de Gestão do Trabalho e da Educação na Saúde. Departamento de Gestão e da Regulação do Trabalho em Saúde. Comitê Nacional Interinstitucional de Desprecarização do Trabalho no SUS. Programa Nacional de Desprecarização do Trabalho no SUS: DesprecarizaSUS - perguntas e respostas. Brasília, DF: Editora do Ministério da Saúde, 2006.

Ministério da Saúde. Secretaria de Gestão do

Trabalho e da Educação na Saúde. Gestão do trabalho e da regulação profissional em saúde: agenda positiva do Departamento de Gestão e da Regulação do Trabalho em Saúde. $3^{\text {a }}$ ed. Brasília, DF: Ministério da Saúde, 2009c.

CAMPOS, G. W. S. A reforma da reforma: repensando a saúde. São Paulo: Hucitec, 1997.

CAMPOS, G. W. S. Apresentação. In: BARROS, M. E. B.; FILHOS SANTOS, S. B. (Org.). Trabalhador de saúde: muito prazer! Protagonismo dos trabalhadores na gestão do trabalho em saúde. Ed. Unijuí, 2007.

FREIRE, P. Pedagogia do oprimido. 12 ed. Rio de Janeiro: Paz e Terra, 1983.

LEFRÈVE, F.; LEFRÈVE, A. M. C. Promoção de saúde: A negação da negação. Rio de Janeiro: Vieira \& Lent, 2004. 
MATTOS, R. A. (Re)visitando alguns elementos do enfoque situacional: um exame crítico de algumas das contribuições de Carlos Matus. Ciênc. Saúde Colet., Rio de Janeiro, v. 15, n. 5, p. 2327-2336, ago. 2010.

NORONHA, J. C.; LIMA, L. D.; MACHADO, C. V. A gestão do Sistema Único de Saúde: características e tendências. In: MINISTÉRIO DA SAÚDE. Saúde no Brasil: Contribuições para a Agenda de Prioridades de Pesquisa. Brasília, DF: 2004, p. 41-94.

QUALIQUANTISOFT. Disponível em: < http://www. spi-net.com.br/registro.asp>. Acesso em: 20 out. 2010.

ROLLO, A. A. É possível valorizar o Trabalho na Saúde num mundo "Globalizado"? In: SANTOS FILHO, S.;

BARROS, M. E. B. de. (Org.) Trabalhador da saúde: muito prazer! Protagonismo dos trabalhadores na gestão do trabalho em Saúde. Ijuí: Ed. Unijuí, 2007, p. 19-60.

SANTIAGO, L. V. As representações sociais na relação teoria-prática: possibilidades de pesquisas. In: COLÓQUIO DE EPISTEMOLOGIA DA EDUCAÇÃO FÍSICA, 5., 2010, Maceió. Anais... Maceió: UFAL, 2010.

Recebido para publicação em fevereiro de 2014

Versão final em outubro de 2014

Conflito de interesses: inexistente

Suporte financeiro: não houve 